\title{
The evolution of floral ontogenetic allometry in the Andean genus Caiophora (Loasaceae, subfam. Loasoideae)
}

DOI:

10.1111/ede.12246

\section{Document Version}

Accepted author manuscript

Link to publication record in Manchester Research Explorer

\section{Citation for published version (APA):}

Strelin, M., Benitez-Vieyra, S., Fornoni, J., Klingenberg, C. P., \& Cocucci, A. (2018). The evolution of floral ontogenetic allometry in the Andean genus Caiophora (Loasaceae, subfam. Loasoideae). Evolution and Development, 20(1), 29-39. https://doi.org/10.1111/ede.12246

\section{Published in:}

Evolution and Development

\section{Citing this paper}

Please note that where the full-text provided on Manchester Research Explorer is the Author Accepted Manuscript or Proof version this may differ from the final Published version. If citing, it is advised that you check and use the publisher's definitive version.

\section{General rights}

Copyright and moral rights for the publications made accessible in the Research Explorer are retained by the authors and/or other copyright owners and it is a condition of accessing publications that users recognise and abide by the legal requirements associated with these rights.

\section{Takedown policy}

If you believe that this document breaches copyright please refer to the University of Manchester's Takedown Procedures [http://man.ac.uk/04Y6Bo] or contact uml.scholarlycommunications@manchester.ac.uk providing relevant details, so we can investigate your claim.

\section{OPEN ACCESS}


$4 \quad$ Marina Strelin ${ }^{1 *}$, Santiago Benitez-Vieyra ${ }^{2,3}$, Juan Fornoni ${ }^{2-4}$, Christian Peter

$5 \quad$ Klingenberg5, Andrea Cocucci ${ }^{2,3}$

$6{ }^{1}$ Laboratorio Ecotono, INIBIOMA (Universidad Nacional del Comahue-CONICET),

$7 \quad$ Pasaje Gutierrez 1125, 8400 Bariloche, Rio Negro, Argentina

$9 \quad{ }^{2}$ Universidad Nacional de Córdoba. Facultad de Ciencias Exactas, Físicas y Naturales.

10 Córdoba, Argentina.

$11{ }^{3}$ Laboratorio de Ecología Evolutiva y Biología Floral, Instituto Multidisciplinario de

12 Biología Vegetal (Consejo Nacional de Investigaciones Científicas y Técnicas-

13 Universidad Nacional de Córdoba), Casilla de Correo 495, X5000ZAA, Córdoba,

14 Argentina.

$15{ }^{4}$ Departamento de Ecología Evolutiva, Instituto de Ecología, Universidad Nacional

16 Autónoma de México, A.P. 70-275, Ciudad de México 04510, México.

$17{ }^{5}$ School of Biological Sciences, University of Manchester, Michael Smith Building,

18 Oxford Road, Manchester M13 9PT, United Kingdom.

20 Running title: Evolution of floral allometry

$22 \quad{ }^{*}$ Corresponding author. E-mail address: marina.strelin85@gmail.com 
The astounding variety of angiosperm flower morphologies has evolved in response to many selective forces. Flower development is highly coordinated and involves developmental associations between size and shape, ontogenetic allometry, which in turn affect the morphology of mature flowers. Although ontogenetic allometries can act as a developmental constraint and may influence adaptive evolution, allometries can evolve themselves and may change rapidly in response to selection.

30 We explored the evolution of ontogenetic allometry in the flowers of 11 Loasoideae 31 species. Seven species belong to Caiophora, which radiated recently in the central Andes, and contains species that are pollinated by bees, hummingbirds and small rodents. According to a previous study, the diversification of Caiophora involved departures from simple allometric scaling, but the changes to allometries that enabled flower diversification have not been explored yet. We characterized the ontogenetic allometry of each species with the methods of geometric morphometrics. We studied the evolution of allometries by constructing allometric spaces, in which the allometry of each species is represented by a point and the arrangement of points indicates the relations among allometric trajectories. To examine the history of changes of ontogenetic allometries, we projected the phylogeny into the allometric spaces. Inspection of allometric spaces suggests that ontogenetic variation is limited to a few dominant features. The allometries of the two main functional flower parts under study differ in their evolutionary labilities, and patterns of variation reflect pollination systems, differences in structural organization, and abiotic environmental factors. 


\section{Introduction}

Flower morphology underwent enormous evolutionary changes, adapting to a wide arrange of environmental conditions, including different mating and pollination scenarios (Fenster et al. 2004; Strauss et al. 2006; Barrett 2013). Duplication, loss or merging of floral structures, homeotic changes of flower organs, and changes in flower symmetry are among the mechanisms that enabled floral structure to evolve (Becker et al. 2011; Endress 2011; Glover et al. 2015). Even among taxa that share the same floral bauplan, evolutionary changes in the sizes, shapes and arrangement of floral structures produced extensive variation in floral morphology (Gardner et al. 2016; Gómez et al. 2016; McCarthy et al. 2016). These changes were accompanied by alterations of floral development, which were reflected in the respective patterns of ontogenetic allometry, the association between size and shape during development.

During development, from the initiation of primordia through anthesis to wilting, flowers undergo coordinated changes in size and shape, resulting in specific patterns of ontogenetic allometry. Evolutionary changes of morphological traits in functional (mature) flowers can occur by extending or truncating ancestral allometric trajectories, a phenomenon that has been discussed as ontogenetic scaling, often in connection to heterochrony (Gould 1975; Klingenberg 1998;Li and Johnston 2000; Strelin et al. 2016a). If changes of this kind evolve readily and the directions of ontogenetic trajectories remain relatively constant, morphological variation among taxa will be concentrated along the trajectories, so that ontogenetic allometry can be viewed as a developmental bias or constraint favoring evolutionary changes along the allometric trajectory (Arthur 2002; Gould 2002; Voje et al. 2013). Yet, ontogenetic allometries can also evolve themselves, and such alterations in allometry may be a mechanism for diversification of floral shapes. Variation in ontogenetic allometries can 
70 involve differences in the pattern of growth-related shape change, as well as differences

71 in the strength of ontogenetic allometries. (Fig. 1). Interestingly, population differences in ontogenetic allometry of flower traits have been found to be associated with differences in pollination systems (Hazle and Canne-Hilliker 2005; Summers et al. 2015). Accordingly, evolutionary changes in ontogenetic allometry of flowers may play adaptive roles and are themselves an important subject of study.

The evolution of allometric patterns can be studied using multivariate ordinations of allometric vectors by principal component analysis (Solignac et al. 1990; Klingenberg and Froese 1991; Klingenberg and Spence 1993), an approach that has more recently been called allometric spaces (Gerber et al. 2008; Wilson and SánchezVillagra 2010). In an allometric space, each point represents the allometry of a taxon, and the relative arrangement of these points, in combination with phylogenetic information, can therefore provide information on the evolution of allometry. Most studies using allometric spaces are based on traditional morphometrics and have characterized ontogenetic allometry as the first principal component of a set of distance measurements (Jolicoeur 1963; Klingenberg 1996). In this study, we extend the approach of allometric spaces to geometric morphometrics (Klingenberg 2010; Zelditch et al. 2012; Dryden and Mardia 2016). Accordingly, we analyze ontogenetic allometry using multivariate regressions of shape of floral structures on their sizes (Monteiro 1999; Klingenberg 2016).

We apply the approach of allometric spaces to examine how ontogenetic allometry evolved in the Andean genus Caiophora (Loasaceae, subfam. Loasoideae). The adaptive radiation in Caiophora involved at least one transition from the ancestral condition of bee- to hummingbird pollination, one transition from hummingbird to small rodent pollination, and at least one reversion from hummingbird to bee pollination 
(Strelin et al. 2017). These transitions were accompanied by changes in flower morphology (Strelin et al. 2016b), and took place during the last $10 \mathrm{Myr}$ (most of them took place during the last $5 \mathrm{Myr}$ ), following the uplift of different Andean mountain ranges (Strelin et al. 2017). This suggests rapid diversification of the genus responding to Andean orogeny and the concomitant changes in the pollination environment (Strelin et al. 2017). Ontogenetic scaling cannot account for the evolution of floral shapes in Caiophora, and there is evidence that significant departures from the ancestral pattern of flower ontogenetic allometry accompanied this diversification (Strelin et al. 2016a). and their rolein morphological diversification. Therefore, it seems promising to use allometric spaces for exploring the evolution of ontogenetic allometry and the specific changes that accompanied the evolution of different pollination strategies. This study investigates ontogenetic allometries of flowersin seven Caiophora species (including bee-, hummingbird- and rodentpollinated species) and four species in their allied bee-pollinated genera, Loasa and Blumenbachia. Ontogenetic allometries for two functional floral parts involved in pollination (corolla and staminode complex) were first characterized using multivariate regression of shape on size in each taxon(Monteiro 1999; Klingenberg 2016). Allometric spaces were then obtained from multidimensional ordinations of ontogenetic allometries using principal component analysis. Finally, the phylogeny of these species was projected into the allometric space (Klingenberg and Ekau 1996; Sidlauskas 2008) to visualize the phylogenetic history of the evolution of ontogenetic allometries. This combination of methods is a powerful approach to investigate how allometries evolve 

and radiated recently into more than 50 species (Ackermann and Weigend 2006; Strelin et al. 2017). Adaptation to vertebrate pollination (Ackermann and Weigend 2006;

Loasoideae presents highly complex flower morphology (Fig. 2A) consisting of a divided corolla with pouch-shaped petals protecting the stamens, and a whorl of five androecium derived staminode complexes. The three outer staminodes of each complex are united into a nectar scale and bear the two inner, free staminodes (Brown and Kaul 1981). This structural complex mediates flower-pollinator fit, conditioning nectar harvesting (Hufford 2003; Ackermann and Weigend 2006). The shapes of the corolla and the staminode complex were under pollinator selection in Loasoideae (Strelin et al. 2016b). Bee-pollinated species have small pendulous flowers, which require the pollinator to land and hold onto the flower by grappling the nectar scales. These flowers present open corollas, which make the nectar scales visible and easy to grasp (Weigend 2004). The staminode complex participates in a stamen release mechanism, which is activated when bees insert their proboscis between the scale and the two protruding staminodes (which block the nectar scale) and move the scale outwards to access the 
144 nectar (Fig. 2B; Weigend et al. 2010). Unlike bee-pollinated species, flowers of 145 hummingbird-pollinated species present narrower corollas and staminode complexes 146 with conspicuous staminodes that noticeably protrude beyond the nectar scale opening.

147 These staminodes ensure the contact of the hummingbird head with fertile flower 148 structures by guiding the pollinator's beak towards the nectar container (Fig. 2C; M. 149 Weigend, pers. comm.). The staminodes are markedly reduced in the rodent pollinated 150 species since they do not participate in pollination (Fig. 2D; Strelin et al. 2016b).

\section{Study design and data collection}

This study includes seven species of Caiophora and four bee-pollinated species of two allied genera, Loasa and Blumenbachia. The sampling of Caiophora includes

154 four bee-pollinated species and two hummingbird-pollinated species. Hummingbirds were also reported to visit Caiophora lateritia, which is one out of the four selected bee-pollinated Caiophora species (Ackermann and Weigend 2006; Strelin et al. 2016b).

157 We also included the single rodent-pollinated species, C. coronata. The sampling for each species included between eight and 25 individual plants of the same population; the number of individuals sampled for each species depended on the availability of plant material in the field (Table S1). One flower in anthesis and four flower buds, covering a range of flower bud diameter from approximately 3 to $20 \mathrm{~mm}$ in large-flowered species

162 and from approximately 3 to $10 \mathrm{~mm}$ in small-flowered species, were sampled from each individual. Samples were kept in $70 \%$ ethanol and later dissected. The petal and the 164 staminode complex were photographed in lateral view using a Leica M420 stereomicroscope (Heerbrugg, Switzerland). 
Because both the corolla and staminode complex structures have a functional

167 role during pollination in Loasoideae, we characterized the size and shape of both with

168 geometric morphometric methods. The petal shape was used to represent corolla shape

169 because developmental changes in the shape of the separate petals are easier to follow

170 than developmental changes in the corolla as a whole.

The tpsDig software (Rohlf 2006) was used to digitize five landmarks on the

\section{Ontogenetic allometry}

To extract shape information from the landmark coordinates, we applied a Procrustes fit using the MorphoJ software (Klingenberg 2011). As a measure of size of each floral structure, centroid size was computed.

Ontogenetic allometry can be described by measuring how several traits covary during growth, e.g. several distance measurements on a structure taken at different developmental stages (Huxley-Jolicoeur school), or as the developmental relationship between the size and the shape of a structure, e.g. how flower proportions change during flower growth (Gould-Mosimann school; for more details on this distinction, see Klingenberg 2016). Fundamentally, these approaches to characterize allometry are logically equivalent, as they both describe how shape changes during growth, and mutually compatible results are expected from both approaches (Klingenberg 2016). In geometric morphometrics, size and shape are usually quantified separately, following the logic of the Gould-Mosimann school (Klingenberg 2016). Accordingly, to 
190 characterize ontogenetic allometry, we used a multivariate regression of the shape

191 (Procrustes coordinates) on the log-transformed centroid size of each flower structure 192 and in each species separately (Monteiro 1999). The log-transformed centroid size was

193 used instead of the raw centroid size, because it yields a more linear relationship 194 between size and shape for ontogenetic allometry (Klingenberg et al. 2012). Because 195 shape changes are often concentrated in the range of smaller sizes in ontogenies and 196 there is relatively little shape change among larger sizes, log-transformation of the size 197 axis often achieves a better linear relationship (Klingenberg et al. 2012; Klingenberg 198 2016) and thus simplifies the comparison of allometric trajectories among taxa. Unlike 199 the Huxley-Jolicoeur approach, where log transformation of measurements is a key part of the theoretical justification why allometric trajectories are expected to be linear 201 (Huxley 1932), the precise form of the relation between size and shape in the GouldMosimann approach is open and therefore investigators are free to choose freely statistical significance of the association between size and shape.

The resulting regression vectors represent the expected change in the relative 207 landmark positions per unit of increase of the log-transformed centroid size. Since the landmarks are homologous among taxa and allometric vectors were computed in the possible to compare the ontogenetic vectors of different taxa directly. allometric regression vectors, which indicates the amount of shape change expected per unit of increase in size. In this study, this quantity is in units of Procrustes distance per unit of increase of log-transformed centroid size, where one unit corresponds to an 
215 increase of centroid size by a factor of 2.718 (Euler's number). The length of the

216 regression vector can be computed as the norm of the vector, which is the square root of

217 its inner product, or equivalently, the square root of the sum of squared regression

218 coefficients (the latter version can be used to compute this quantity with any

219 spreadsheet from standard output of morphometrics or statistics programs). For testing 220 the presence of a phylogenetic signal in the strength of allometry, we used a 221 permutation test that simulates the null hypothesis of no phylogenetic signal by 222 randomly swapping the values among taxa (Laurin 2004), with 10,000 repeats of the 223 swapping procedure for each test.

\section{Allometric spaces} allometric spaces were obtained (Klingenberg and Froese 1991; Gerber et al. 2008). Each dimension of an allometric space expresses variation among taxa in the growthrelated changes for the respective shape variable. The allometry of each taxon is 229 represented by a point in this allometry space, and distances between points represent 230 differences between ontogenetic allometries (Fig. 1). Allometric spaces are obtained 231 from a multivariate ordination of allometric vectors, usually using principal components 232 of the vectors themselves (Klingenberg and Froese 1991; Klingenberg and Spence 1993; Gerber et al. 2008; Wilson and Sánchez-Villagra 2010; Wilson 2013). An alternative method, which is likely to give broadly similar results in practice, is to use a multidimensional scaling analysis based on the angles between allometric vectors (Frédérich and Vandewalle 2011; Urošević et al. 2013).

For each flower structure, the ontogenetic vectors obtained from multivariate regression analyses for the 11 taxa were used as observations in a principal component 
analysis (PCA) to analyze the allometric spaces (Klingenberg and Froese 1991;

240 Klingenberg and Spence 1993). The PCA needs to use the covariance matrix of the

241 allometric vectors (and not the correlation matrix, which is the default in many statistics

242 programs) because the scaling of variables of the ontogenetic vectors reflects the

243 allometry that is of interest, and any standardization would destroy this scaling (and, in

244 the context of geometric morphometrics, also the scaling that reflects the Procrustes

245 geometry). Because the allometric vectors have the same variables as the morphospace

246 in which allometry is characterized (log-transformed measurements in traditional

247 morphometrics, landmark coordinates in geometric morphometrics), the allometric

248 space and corresponding morphospace share the same coordinate system and are thus

249 closely related. In the context of geometric morphometrics, it is therefore possible to use

250 the usual tools for visualizing shape changes (Klingenberg 2013) to display the

251 morphological meaning of the PC axes. Because the observations in the PCA are

252 allometric vectors for the taxa in the study, the PCs obtained in the analysis are those

253 axes that account for the maximum amount of variation among allometries of different

254 taxa. For this study, ontogenetic vectors were imported into R (R Core Team 2016),

255 where two separate PCAs (one for each flower structure) were run using the function

256 prcomp. The resulting PC coefficients (eigenvectors) were imported back into MorphoJ

257 (Klingenberg 2011) in order to visualize the changes in allometric vectors associated to

258 each PC.

To investigate the evolutionary history of changes in allometry, we projected the phylogeny of Loasoideae (Strelin et al. 2017), pruned to include onlythe 11 species for 261 which ontogenetic allometry data were available, into the scatter plots of the first two 262 PCs of allometric spaces (Klingenberg and Ekau 1996; Sidlauskas 2008; Gómez et al. 263 2016; Strelin et al. 2016a). The position of internal nodes in the allometric spaces was 
determined following Sidlauskas (2008), using a maximum-likelihood algorithm which is mathematically equivalent to weighted squared-change parsimony (Sidlaukas 2008). This was done with the phylomorphospace function of the phytools package in $\mathrm{R}$ (Revell 2012). In analogy with the expression "phylomorphospace" (Sidlauskas 2008) for scatter plots showing a phylogeny projected into a space derived from a morphometric analysis, it might seem tempting to coin an expression such as "phyloallometric space" (to call it phylomorphospace would be incorrect because we are dealing with an allometric space, not a morphospace). We recommend against this type of name, however, because it might suggest to unwary readers that there is something special about the space in relation to phylogeny. Such an impression would be mistaken, because the underlying space (allometric space or morphospace) is exactly the same whether or not a phylogeny is projected into it - the space is altered no more than drawing a phylogenetic tree onto a sheet of paper transforms it into a "phylopaper".

As a statistical assessment of the phylogenetic signal in the variation of allometries among species, we used a permutation test that simulated the null hypothesis of no phylogenetic signal by randomly exchanging allometric vectors among taxa, a direct equivalent of a test widely used to assess the phylogenetic signal in the average shapes of species (Klingenberg and Gidaszewski 2010). For each floral structure, the permutation test used 10,000 randomization rounds.

\section{Results}

\section{Ontogenetic allometries}

The permutation tests associated with the regression analyses indicated that all taxa displayed statistically significant ontogenetic allometry $(P<0.0001$ in all cases). 
Size predicted between $16.57 \%$ and $62.84 \%$ of shape variation within taxa for the petal and between $9.38 \%$ and $50.84 \%$ for the staminode complex (Table 1).

The shape changes associated with ontogenetic allometry differed among taxa, but there were also general patterns shared among them (Fig. 3). Petal growth in all species involves a progressive straightening of the petal base associated with opening of the flower (Fig. 3). The extent of this straightening differs to some degree among taxa. Furthermore, in some species such as C. lateritia and L. acerifolia, a relative reduction in the size of the tip of the petal takes place during growth. For the staminode complex, a common feature is that the nectar scale overgrows the staminode, more so in some species such as L. bergii, C. nivalis, or C. coronata than in others such as $C$. chuquitensis or C. hibiscifolia (Fig. 3). Furthermore, in some species such as L. acerifolia, B. insignis, B. silvestris, and C. coronata, there is a reduction of the angle between the main axes of the nectar scale and the staminode, but there are also some species where this angle becomes larger during growth, such as $C$. hibiscifolia and $C$. dumetorum.

Comparisons of the strengths of ontogenetic allometry showed that, for the petals, the allometries tend to be weaker in Caiophora than in species in its allied genera (except for C. lateritia; Table1). In accordance with this impression, the permutation test found a statistically significant phylogenetic signal for the strength of allometry in petals $(P=0.021)$. Overall, species in Caiophora tend to undergo less change in petal shape per unit of increase in log-transformed centroid size than species in its allied genera (Table 1). For the staminode complex, the strength of ontogenetic allometry varies substantially and without any apparent relationship to phylogeny or pollinators (Table 1), and the permutation test found no significant phylogenetic signal $(P=0.73)$. The ontogenetic allometries of the hummingbird pollinated species, $C$. 
hibiscifolia and C. chuquitensis, are among the weakest in this study, both for the petal 313 and the staminode complex (Table 1).

\section{Allometric spaces}

For the petals, the first two PCs accounted for $44.17 \%$ and $37.75 \%$ of the total variance among allometric vectors of the 11 taxa, whereas for the staminode complex, the first two PCs took up $67.02 \%$ and $30.44 \%$ of the total variance. Two dimensions were therefore sufficient to summarize more than $80 \%$ of the variation among the allometric vectors for the petal and nearly all the variation for the staminode complex.

For the petals, the PC1 primarily represents variation between allometries for which the straightening of the base is weaker (Fig. 3, negative values of $\mathrm{PC}_{\mathrm{P}}$ ) or stronger (positive values of $\mathrm{PC} 1_{\mathrm{P}}$ ). This change is combined with differential expansion of the portion of the petal between landmarks 3 and 4 versus the two adjacent regions (between landmarks 2 and 3, 4 and 5; in favor of the middle portion for negative values of $\mathrm{PC}_{\mathrm{P}}$, in favor of the adjacent regions for positive values of $\left.\mathrm{PC} 1_{\mathrm{P}}\right)$. The $\mathrm{PC} 2$ for petals mainly represents variation in the disproportionate growth of the two distal parts of the petals, with some allometries featuring a greater relative contraction of the distalmost portion between landmarks 1 and 2 (Fig. 3, positive values of $\mathrm{PC} 2 \mathrm{P}$ ) and others with a weaker relative contraction (negative values of $\mathrm{PC}_{\mathrm{P}}$, appearing as a relative expansion in the diagram). For the staminode complex, the PC1 represents variation in the degree to which the nectar scale overgrows the staminodes, which is only relatively weak in the allometries of some taxa (Fig. 3, negative values of $\mathrm{PC} 1_{\mathrm{St}}$ ) but very pronounced for the allometries of other taxa (positive values of $\mathrm{PC} 1_{\mathrm{St}}$ ). The $\mathrm{PC} 2$ for the staminode complex stands mainly for variation in the allometric changes of the angle at which the staminodes emerge from the nectar scale: this angle narrows during growth 
for allometries corresponding to negative values of $\mathrm{PC} 2_{\mathrm{St}}$, whereas the angle widens for allometries with positive values of $\mathrm{PC} 2_{\mathrm{St}}$.

Projecting the phylogeny into the allometric spaces shows the patterns of evolutionary divergence of ontogenetic allometries (Fig. 3).For both floral structures, the allometries of the different taxa occur in regions of the allometric space that are more or less separated between species of Caiophora and its allied genera. In the allometric space for the petals, all Caiophora species, except for the early diverged $C$. nivalis, are clustered together in a limited region toward the lower-left of the plot in Figure 3, suggesting that they share fairly similar and phylogenetically derived petal allometries. In accordance with this, the permutation test indicated a statistically significant phylogenetic signal $(\mathrm{P}<0.0001)$. By contrast, for the staminodial complex, ontogenetic allometries diverged markedly among the species of Caiophora, with substantial divergence even among closely related species, whereas the variation among the remaining taxa is fairly limited. The permutation test found no significant phylogenetic signal for the allometries of the staminodial complex $(P=0.20)$. Intriguingly, the two hummingbird-pollinated species included in this study (species 6 and 8 in Figure 3) occupy extreme positions in both allometric spaces.

\section{Discussion}

This study explored the evolution of ontogenetic allometry in flowers of 11 Loasoideae species. It extends an earlier study reporting that ontogenetic scaling is not a sufficient explanation to account for the range of floral shapes in this group (Strelin et al. 2016a), raising the questions whether and how ontogenetic allometries themselves evolve. As a tool to address these questions, we have used allometric spaces, a method that has long been used in traditional morphometrics, but not yet in the context of 
geometric morphometrics. Exploring the structure of allometric spaces and the

361 distribution of taxa within them provides insight into the evolution of ontogenies in the

362 Loasoideae and suggests possible adaptive connections to pollination systems.

The analysis of allometric spaces indicated that the first two dimensions accounted for more than $80 \%$ and $90 \%$ of the total variation in ontogenetic allometries for the two floral structures under study. For 11 taxa, the number of dimensions of the allometric space is ten (one degree of freedom is lost for the overall mean), as it would for any other phenotypic spaces, including morphospaces. That just two of the available ten dimensions account for the vast majority of variation suggests that evolutionary changes in allometric trajectories were concentrated mainly in a few morphological features of the two floral structures. Accordingly, two-dimensional plots (Fig. 3) provide a mostly complete picture of the allometric spaces and thus the evolution of ontogenetic allometries.

The diversification of Caiophora involved the colonization of new regions in the allometric spaces both for the petal and the staminode complex (Fig. 3). Whereas the area of the petal allometric space colonized by Caiophora is smaller than that occupied by species in its allied genera, this is not the case for the allometric space of the staminode complex, where the area occupied by Caiophora is comparatively larger (Fig 3). In the allometric space for petals, ancestral state estimation yielded a scenario where many terminal branches were relatively short (i.e. there were relatively small changes in allometries), whereas the internal nodes tended to be clearly separated (Fig. 3). By contrast, in the allometric space for the staminode complex, internal branches tended to be shorter than terminal branches, so that even closely related species can drastically diverge from each other (Fig. 3). This pattern is in agreement with the statistically significant phylogenetic signal for petal allometry (both in the strength and type of 
growth related shape changes) and with the lack of a significant phylogenetic signal for the allometry of the staminode complex. While the petal can be considered a unitary structure, the staminode complex of Loasoideae is modular as it is composed of two separate but coupled subunits: the nectar scale and the staminode (Hufford 2003). The lack of phylogenetic signal in the allometry of this structure may relate to its modularity, which may render its development and thus ontogenetic allometry more evolutionarily labile than the unitary petal (Diggle 2014).

Inspection of the allometric spaces for both structures suggests that the variation of ontogenetic allometries is linked to the mode of pollination. For both allometric spaces, the two hummingbird-pollinated species (C. hibiscifolia and C. chuquitensis) are close to each other, but in an extreme position in relation to the other taxa, and the presumably partly hummingbird-pollinated C. lateritia is also nearby (Fig. 3). The rodent-pollinated $C$. coronata is in near-extreme positions in both allometric spaces, close to the hummingbird-pollinated taxa for the petals and far from them for the staminode complex (Fig. 3). Mature flowers in hummingbird-pollinated Caiophora species tend to present narrow corollas (with petals bent at their bases) and staminode complexes with the staminodes protruding noticeably from the nectar scale opening, when compared to bee and small rodent pollinated species (Fig. 2B,C; Strelin et al. 2016b). The narrow corollas and the elongated staminode tips guide the hummingbird beak towards the nectar containers, ensuring the contact of the hummingbird head with fertile flower structures (Fig. 2C). Flowers of the rodent-pollinated C. coronata have a partially open corolla, with staminodes almost enclosed by the nectar scale (Fig. 2D; Cocucci and Sérsic 1998).

Abiotic environmental factors may also play a role in the evolution of ontogenetic allometries. In the allometric space of the petals, the Caiophora species 
were separated from the species of the allied genera in a region that corresponds to

411 allometries involving an incomplete unfolding of the corolla, maintaining a clear angle

412 at the petal base (Fig. 3). By contrast, there was no such separation in the allometric

413 space of the staminode complex (Fig. 3). Whereas Loasa and Blumenbachia are 414 lowland lineages ( $<1000$ m.a.s.1.), most of the Caiophora species are associated to the 415 Andes and grow at intermediate (1500-3000 ma.s.1.) to high elevations (>3000 ma.s.1.; 416 Ackermann and Weigend 2006). When compared to lowland lineages, Caiophora plants 417 therefore experience greater exposure to UV-B radiation. It has been demonstrated that 418 UV-B radiation plays an important role in the evolution of protective floral forms in 419 alpine plants, since UV-B is detrimental for male and female plant fitness (Wang et al. 2010). Protective floral forms evolving at high altitudes include down-facing flowers (Wang et al. 2010), and tubular corollas (Zhang et al. 2014). The retention of partially bud-like corollas in Caiophora, independently of the pollination system, may convey protection to fertile flower structures from UV-B damage.

The strength of ontogenetic allometry for both floral structures varied extensively among the species included in this study (Table 1). Evolutionary changes in the strength of ontogenetic allometry can produce heterochronic changes (Alberch et al. 1979; Klingenberg 1998). The evolution of weaker ontogenetic allometry can result in paedomorphic, or underdeveloped, shape features, since it involves attainment of reproductive maturity (flower anthesis in our study) with a shape that corresponds to earlier developmental stages in the ancestor. Conversely, comparatively stronger ontogenetic allometries can give rise to peramorphic, or overdeveloped, shape features. Note that evolutionary changes in the initial shape, the size at maturity and the direction of the allometric trajectory can complicate these relationships. Although we did not find a clear match between the strength of ontogenetic allometries and pollination systems, 
ontogenetic allometries for both the petal and the staminode complex are weak in the two hummingbird-pollinated species (C. hibiscifolia and C. chuquitensis). This may suggest concerted evolution of paedomorphic features in both floral structures of hummingbird-pollinated species (Table 1). Interestingly, evolution of hummingbirdpollinated flowers from a presumably bee-pollinated ancestor via paedomorphosis was already reported for Delphinium (Ranunculaceae) by Guerrant (1982). Such consistent variation in the strengths of the allometries of both flower organs was not seen in all taxa. For instance, ontogenetic allometry in C. coronata was relatively weak for the petals and strong for the staminode complex (Table 1). As ontogenetic allometries of petals in Caiophora tend to be weaker than in Loasa and Blumenbachia species (Table 1), the relation of petal allometry with phylogeny or altitude holds for the strength of allometry just as it does for the allometric space. For the staminode complex, by contrast, Loasa and Blumenbachia have allometries of intermediate strengths, whereas species of Caiophora have both the strongest and weakest allometries (Table 1), suggesting evolution of allometries from intermediate ancestors to both extremes in Caiophora.

The relationships of ecological factors such as pollination mode and altitude with the position of taxa in allometric spaces are reminiscent of the results of previous studies in animals, where patterns of ontogenetic allometry were found to relate to diet or habitat (Wilson and Sánchez-Villagra 2010; Frédérich and Vandevalle 2011; Urošević et al. 2013; Wilson 2013). Direct comparisons are difficult, however, because the methods for characterizing allometric spaces used in this study differ slightly from those in the previous studies. Most previous studies of allometric spaces were based on traditional morphometric traits (Klingenberg and Froese1991; Klingenberg and Spence 1993; Gerber et al. 2008; Wilson and Sánchez-Villagra 2010; Wilson 2013). There are 
460 differences even to the rare studies using geometric morphometrics, because they used 461 computations that normalized allometric vectors to unit length (focusing on the angles 462 between vectors), so that the strength of allometry was not included as a component of 463 variation (Frédérich and Vandevalle 2011; Urošević et al. 2013). A full comparison of 464 methods is beyond the scope of this paper, and will be presented elsewhere. 465 Nevertheless, it is clear that the use of allometric spaces in the framework of geometric 466 morphometrics provides powerful analytical tools for the comparative analysis of 467 ontogenetic allometry, which is still a largely unexplored area of evolutionary 468 developmental biology.

\section{ACKNOWLEDGEMENTS}

We thank Maximilian Weigend and Markus Ackermann for providing information 471 about the natural history of species in Loasoideae. We thank Martin Diller, Alicia 472 Sérsic, Jorge Strelin, Adrián Strelin and Leonardo Torielli for helping with the field 473 work, and Guillermo Amico for providing plant material of one of the species in this 474 study. We also thank the anonymous reviewers for contributing with their comments 475 and suggestions to the quality of this manuscript. M.S. has a postdoctoral scholarship 476 from the National Scientific and Technical Research Council (CONICET). Studies were 477 funded by following grants to AC: FONCYT (BID 2012 PICT 1553) and from SECYT$478 \quad$ UNC (2011-2015). 


\section{REFERENCES}

480 Ackermann, M., Weigend, M. 2006. Nectar, floral morphology and pollination 481 syndrome in Loasaceae subfam. Loasoideae (Cornales). Annals of Botany 98: 503-514

Alberch, P., Gould. S. J., Oster, G. F., Wake, D. B. 1979. Size and shape in ontogeny and phylogeny. Paleobiology5: 296-371

Arthur, W. 2002. The interaction between developmental bias and natural selection: from centipede segments to a general hypothesis. Heredity 89:239-246.

Barrett, S.C. 2013. The evolution of plant reproductive systems. How often are transitions irreversible? Proceedings of the Royal Society B. 280: 20130913

Becker, A., Alix, K., Damerval, K. 2011. The evolution of flower development: current understanding and future challenges. Annals of Botany 107: 1427-1431

Brown, D. K., Kaul, R.B. 1981. Flower structure and mechanism in Loasaceae. coronata (Loasaceae). Plant Systematics and Evolution, 211: 113-128.

Diggle, P. K. 2014. Modularity and intra-floral integration in metameric organisms: 495 plants are more than the sum of their parts. Philosophical Transactions Royal Society $496 \quad B, 369$ (1649), 20130253. Chichester, Wiley. 
499 Endress, P. K. 2011. Evolutionary diversification of the flowers in $500 \quad$ angiosperms. American Journal of Botany, 98: 370-396.

501 Fenster, C. B., Armbruster, W. S., Wilson, P., Dudash, M. R., Thomson, J. D. 2004.

502 Pollination syndromes and floral specialization. Annual Review of Ecology, Evolution, 503 and Systematics, 375-403.

504 Frédérich, B., Vandewalle, P. 2011. Bipartite life cycle of coral reef fishes promotes 505 increasing shape disparity of the head skeleton during ontogeny: an example from 506 damselfishes (Pomacentridae). BMC Evolutionary Biology 11: 1.

507 Gardner, A. G., Fitz Gerald, J. N., Menz, J., Shepherd, K. A., Howarth, D. G., Jabaily, 508 R. S. 2016. Characterizing floral symmetry in the Core Goodeniaceae with geometric 509 morphometrics. PLoS ONE11:e0154736.

510 Gerber, S., Eble, G. J., Neige, P. 2008. Allometric space and allometric disparity: a 511 developmental perspective in the macroevolutionary analysis of morphological 512 disparity. Evolution 62: 1450-1457.

513 Glover, B. J., Airoldi, C.A., Brockington, S.F., Fernández-Mazuecos, M., Martínez514 Pérez, C., et al. 2015. How have advances in comparative floral development influenced 515 our understanding of floral evolution? International Journal of Plant Sciences 176: 307516323.

517 Gómez, J. M., R. Torices, J. Lorite, C. P. Klingenberg, Perfectti, F. 2016. The role of pollinators in the evolution of corolla shape variation, disparity and integration in a 
highly diversified plant family with a conserved floral bauplan. Annals of Botany 117:

$520 \quad 889-904$.

521 Good, P. 2000. Permutation tests: a practical guide to resampling methods for testing 522 hypotheses. New York, Springer.

Gould, S. J. 1975. Allometry in primates, with emphasis on scaling and the evolution of the brain. Contributions to Primatology 5: 244-292.

Gould S. J.2002. Chapter 10: The Integration of Constraint and Adaptation (Structure and Function) in Ontogeny and Phylogeny: Historical Constraints. In: The Structure of Evolutionary Theory. Cambridge, MA: The Belknap Press of Harvard University Press.

Guerrant Jr. E. O. 1982. Neotenic Evolution of Delphinium nudicaule (Ranunculaceae): A Hummingbird-Pollinated Larkspur. Evolution 36: 699-712

Hazle, T., Canne-Hilliker, J. 2005. Floral ontogeny and allometry of Mimulus cardinalis: interpopulational variation and traits of the hummingbird-pollination syndrome. International Journal of Plant Sciences. 166: 61-83.

Hufford, L. 2003. Homology and developmental Transformation: models for the origins of the staminodes of Loasaceae Subfamily Loasoideae. International Journal of Plant Sciences 164: 409-439.

Huxley, J. S. 1932, Problems of relative growth. Baltimore, Johns Hopkins University Press.

Jolicoeur, P. 1963. The multivariate generalization of the allometry equation. Biometrics 19: 497-499. 
541 Klingenberg, C. P., Froese, R. 1991. A multivariate comparison of allometric growth 542 patterns. Systematic Zoology 40: 410-419.

543 Klingenberg, C. P., Spence, J. R. 1993. Heterochrony and allometry: lessons from the $544 \quad$ water strider genus Limnoporus. Evolution 47: 1834-1853.

545 Klingenberg, C. P., Ekau, W. 1996. A combined morphometric and phylogenetic 546 analysis of an ecomorphological trend: pelagization in Antarctic fishes (Perciformes: 547 Nototheniidae). Biological Journal of the Linnean Society 59: 143-177.

548 Klingenberg, C. P. 1996. Multivariate allometry, Pages 23-49 in L. F. Marcus, M. Corti, 549 A. Loy, G. J. P. Naylor, and D. E. Slice, eds. Advances in morphometrics. New York, $550 \quad$ Plenum Press.

551 Klingenberg, C. P. 1998. Heterochrony and allometry: the analysis of evolutionary 552 change in ontogeny. Biological Reviews 73: 79-123

553 Klingenberg, C. P. 2010. Evolution and development of shape: integrating quantitative $554 \quad$ approaches. Nature Reviews Genetics 11: 623-635.

555 Klingenberg, C. P., Gidaszewski, N. A. 2010. Testing and quantifying phylogenetic 556 signals and homoplasy in morphometric data. Systematic Biology 59: 245-261.

557 Klingenberg, C. P. 2011. MorphoJ: an integrated software package for geometric 558 morphometrics. Molecular Ecology Resources 11: 353-357

559 Klingenberg, C.P., Duttke, S., Whelan, S., Kim, M. 2012. Developmental plasticity, 560 morphological variation and evolvability: a multilevel analysis of morphometric 561 integration in the shape of compound leaves. Journal of Evolutionary Biology 25: 115562 129. 
563 Klingenberg, C. P. 2013. Visualizations in geometric morphometrics: how to read and 564 how to make graphs showing shape changes. Hystrix 24:15-24.

565 Klingenberg, C. P. 2016. Size, shape, and form: concepts of allometry in geometric 566 morphometrics. Development Genes and Evolution 226: 113-137.

567 Laurin, M. 2004. The evolution of body size, Cope's rule and the origin of amniotes. $568 \quad$ Systematic Biology 53: 594-622.

569 Li, P., Johnston, M. O. 2000. Heterochrony in plant evolutionary studies through the $570 \quad$ twentieth century. Botanical Review 66: 57-88.

571 McCarthy, E. W., Chase, M. W., Knapp, S., Litt, A., Leitch, A. R., Le Comber, S. C. 572 2016. Transgressive phenotypes and generalist pollination in the floral evolution of $573 \quad$ Nicotianapolyploids. Nature Plants 2: 16119.

574 Monteiro L. 1999. Multivariate regression models and geometric morphometrics: the 575 search of causal factors in the analysis of shape. Systematic Biology 48: 192-199.

576 R Core Team. 2016. R: A language and environment for statistical computing. R 577 Foundation for Statistical Computing, Vienna, Austria. URL http://www.R-project.org/

578 Revell, L. J. 2012. phytools: an R package for phylogenetic comparative biology (and 579 other things). Methods in Ecology and Evolution 3: 217-233.

580 Rohlf, F. J. 2006. TPS seriessoftware. Available at: http://life.bio.sunysb.edu/morph/

581 Sidlauskas, B. 2008. Continuous and arrested morphological diversification in sister 582 clades of characiform fishes: a phylomorphospace approach. Evolution 62: 3135-3156. 
Solignac, M., Cariou, M. L., Wimitzky, M. 1990. Variability, specificity and evolution 584 of growth gradients in the species complex Jaera albifrons (Isopoda, $585 \quad$ Asellota). Crustaceana, 59: 121-145.

Strauss, S. Y., Whittall, J. B. 2006. Non-pollinator agents of selection on floral traits. Ecology and evolution of flowers, 120-138.

Strelin, M. M., Benitez-Vieyra, S., Fornoni, J., Klingenberg, C. P., Cocucci, A. A. 2016a. Exploring the ontogenetic scaling hypothesis during the diversification of pollination syndromes in Caiophora (Loasaceae, subfam. Loasoideae). Annals of Botany 117: 937-947

Strelin, M. M., Benitez-Vieyra, S., Ackermann, M., Cocucci, A. A. 2016b. Flower reshaping in the transition to hummingbird pollination in Loasaceae subfam. Loasoideae despite absence of corolla tubes or spurs. Evolutionary Ecology 30: 401-417 Strelin, M. M., Arroyo, J. I., Fliesswasser, S., Ackermann, M. 2017. Diversification of Caiophora (Loasaceaesubfam. Loasoideae) during the uplift of the Central $597 \quad$ Andes. Organisms Diversity \& Evolution, 17: 29-41. allometry suggests repeated transitions between selfing and outcrossing in a mixed $600 \quad$ mating plant. American Journal of Botany: 102: 745-757.

601 Urošević, A., Ljubisavljević, K., Ivanović, A. 2013. Patterns of cranial ontogeny in 602 lacertid lizards: morphological and allometric disparity. Journal of Evolutionary 603 Biology 26: 399-415.

604 Voje, K. L., Hansen, T. F., Egset, C. K., Bolstad, G. H., Pélabon, C. 2013. Allometric 605 constraints and the evolution of allometry. Evolution 68: 866-885. 
606 Wang, Y., Meng, L. H., Yang, Y. P., Duan, Y. W. 2010. Change in floral orientation in 607 Anisodusluridus (Solanaceae) protects pollen grains and facilitates development of 608 fertilized ovules. American Journal of Botany 97: 1618-1624.

609 Weigend, M. 2004. Four new species of Nasa ser. Alatae (Loasaceae) in the Amotape610 Huancabamba zone of Peru. Novon: 134-146.

611 Weigend, M., Ackermann, M., Henning, T. 2010. Reloading the revolver-male fitness 612 as a simple explanation for complex reward partitioning in Nasa macrothyrsa 613 (Loasaceae, Cornales). Biological Journal of the Linnean Society, 100, 124-131.

614 Wilson, L. A. B. 2013. Allometric disparity in rodent evolution. Ecology and Evolution $615 \quad 3: 971-984$

616 Wilson, L. A. B., Sánchez-Villagra, M. R. 2010. Diversity trends and their ontogenetic 617 basis: an exploration of allometric disparity in rodents. Proceedings of the Royal Society 618 of London, B Biological Sciences 277: 1227-1234.

619 Zhang, C., Yang, Y. P., Duan, Y. W. 2014. Pollen sensitivity to ultraviolet-B (UV-B) 620 suggests floral structure evolution in alpine plants. Scientific reports, 4: 04520.

621 Zelditch, M. L., D. L. Swiderski, and H. D. Sheets. 2012. Geometric morphometrics for 622 biologists: a primer. Amsterdam, Elsevier. 
626 Table 1. The strength of ontogenetic allometry (in units of Procrustes distance per unit 627 of increase in log-transformed centroid size, corresponding to an increase by a factor of 628 2.718), and percentage of shape variation explained by size in each species.

\begin{tabular}{lcccc}
\hline Species & \multicolumn{2}{c}{ Petal } & \multicolumn{2}{c}{ Staminodial complex } \\
\hline & Strength & $\%$ shape & Strength & \% shape \\
& & variation & & variation \\
\hline Blumenbachia insignis & 0.259 & $54.22 \%$ & 0.227 & $24.98 \%$ \\
Blumenbachia silvestris & 0.291 & $62.84 \%$ & 0.168 & $18.02 \%$ \\
Loasa acerifolia & 0.208 & $49.21 \%$ & 0.349 & $50.06 \%$ \\
Loasa bergii & 0.266 & $41.71 \%$ & 0.432 & $33.45 \%$ \\
Caiophora chuquitensis & 0.151 & $46.01 \%$ & 0.085 & $9.38 \%$ \\
Caiophora clavata & 0.191 & $45.87 \%$ & 0.389 & $30.50 \%$ \\
Caiophora coronata & 0.166 & $35.60 \%$ & 0.515 & $34.48 \%$ \\
Caiophora dumetorum & 0.193 & $52.31 \%$ & 0.478 & $50.84 \%$ \\
Caiophora hibiscifolia & 0.104 & $42.11 \%$ & 0.185 & $45.52 \%$ \\
Caiophora lateritia & 0.235 & $51.67 \%$ & 0.168 & $19.68 \%$ \\
\hline Caiophora nivalis & 0.137 & $16.67 \%$ & 0.599 & $35.15 \%$ \\
\hline
\end{tabular}



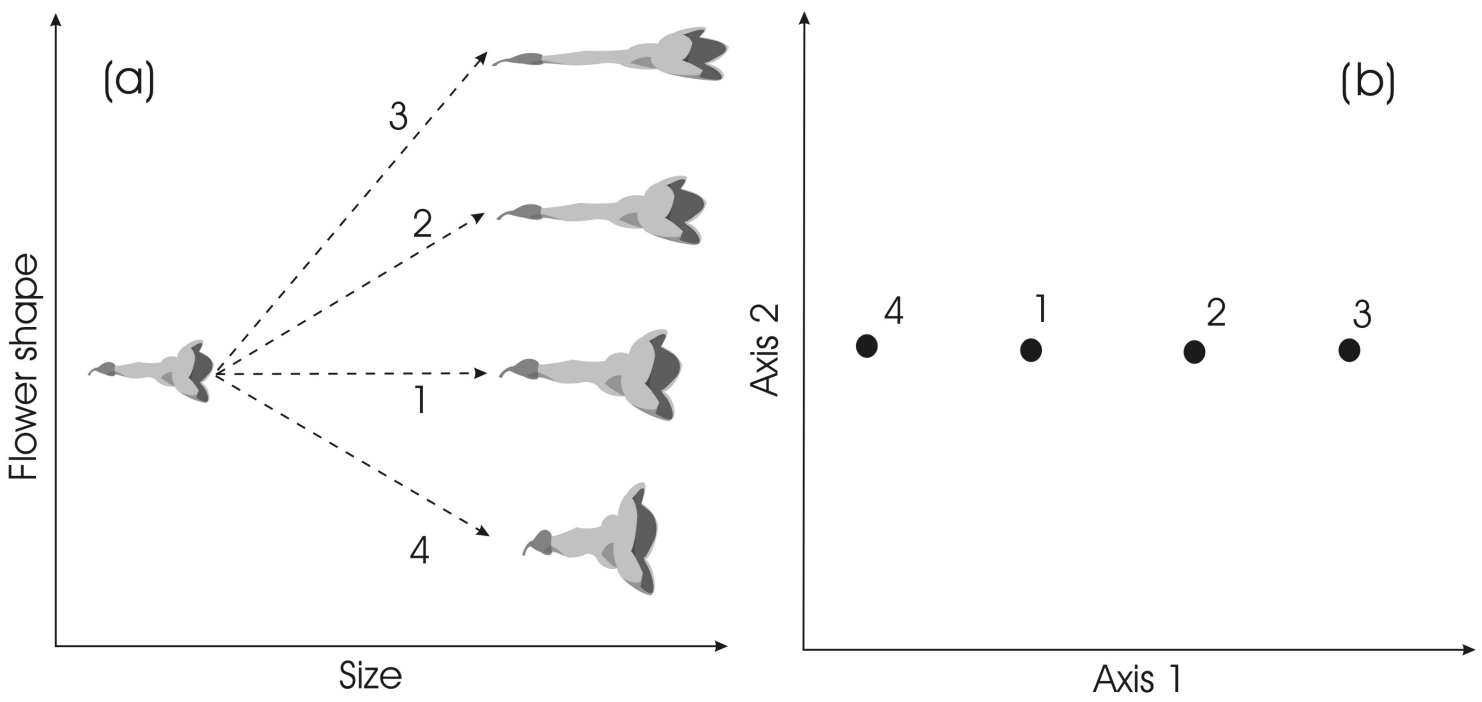

Figure 1. Variation of allometries as plots of shape versus size and in the corresponding allometric space. (a) Four hypothetical examples of different ontogenies. Taxon 1 shows isometric growth, with no shape change. Taxa 2 and 3 have the same type of allometric shape change, but taxon 3 has a stronger allometry than taxon 2 because it has a greater

637 shape change per unit of increase in size. Taxon 4 has an allometric shape change that is 638 the opposite of the change in taxa 2 and 3, but the strength of allometries is the same in taxa 2 and 4.(b) The allometric space, in which each of the allometries is represented by 640 a single point. Because the allometries in this simplified example only involve a single 641 aspect of shape (elongation versus shortening/widening, the vertical axis in panel (a)), 642 they occupy only one dimension in the allometric space (no variation along axis 2). 

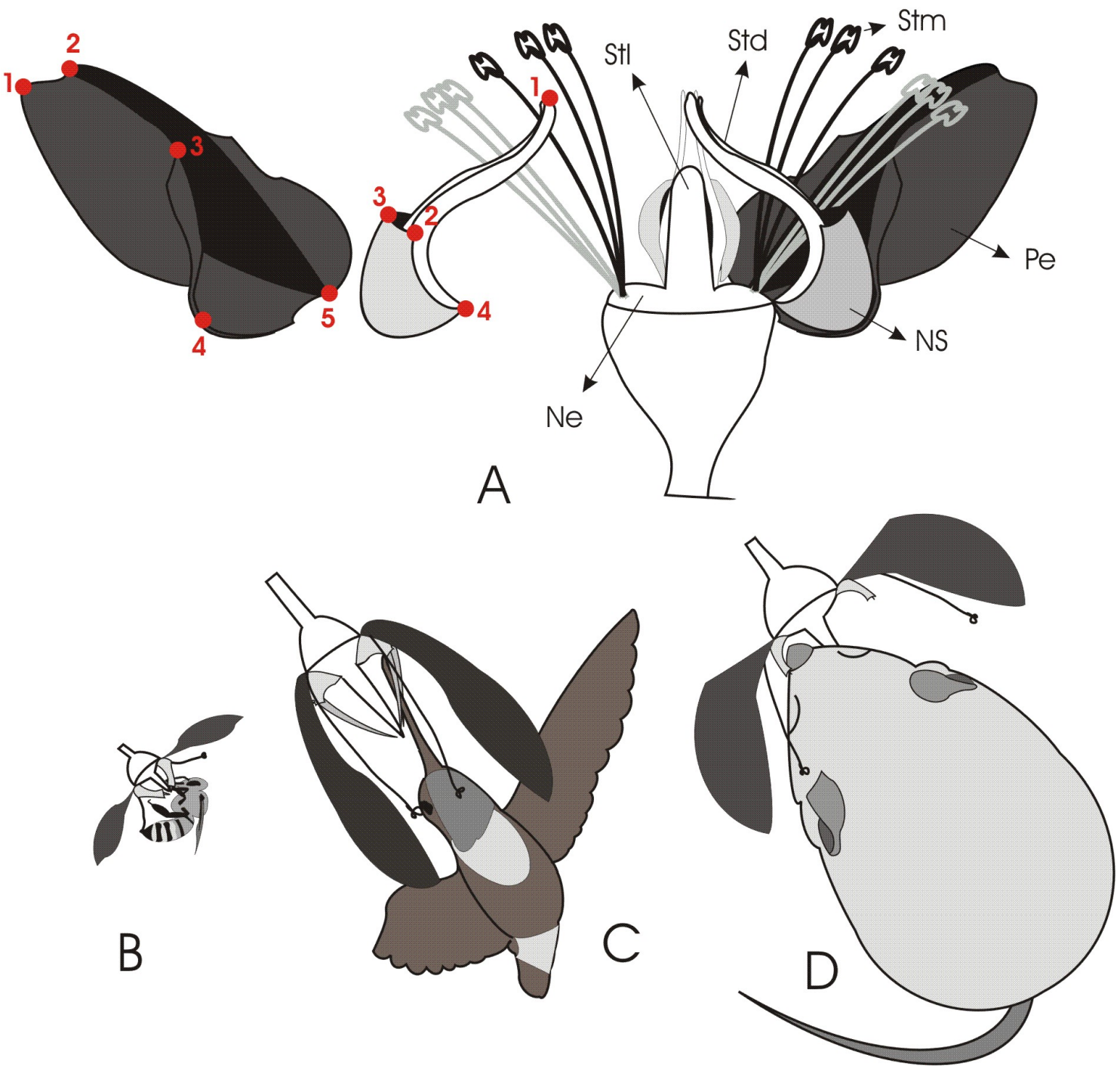

644 Figure 2. Loasoideae flowers and pollination modes. (A) Schematic representation of a 645 typical Loasoideae flower, indicating the name of each floral structure: $\mathrm{Pe}=$ petal; $\mathrm{NS}=$ 646 nectar scale; $\mathrm{Std}=$ staminode; $\mathrm{Stm}=$ stamen; $\mathrm{Stl}=$ style; $\mathrm{Ne}=$ nectary. The landmarks 647 representing the shape of the petal and the staminode complex are in red (numbers correspond to those in Figure S2).(B) Bee-pollinated flower.(C) Hummingbird649 pollinated flower.(D) Flower of Caiophora coronata, the species pollinated by small rodents. Notice the reduced staminodes. 

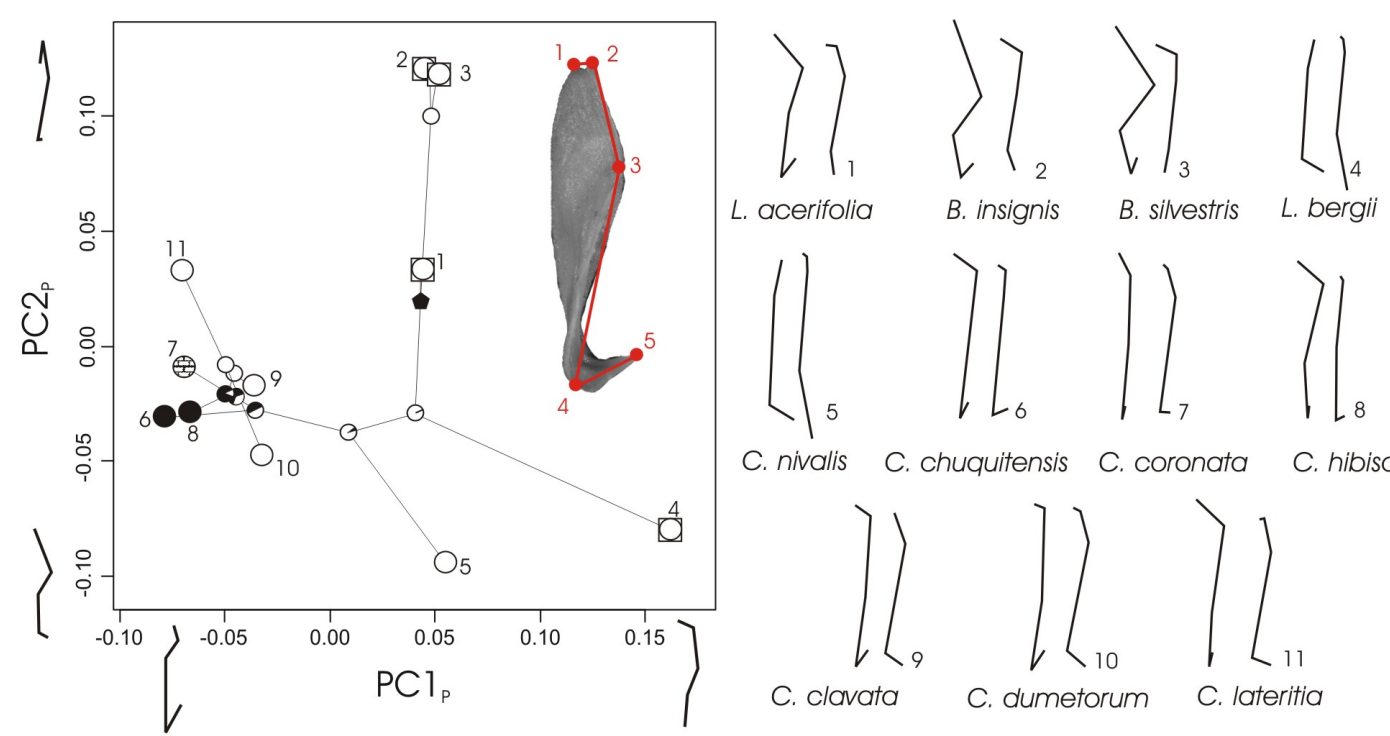

B. insignis

B. silvestris

L. bergii
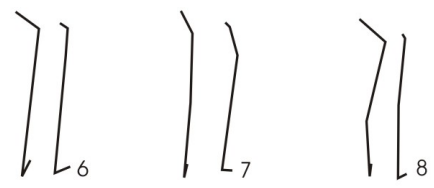

C. nivalis

C. chuquitensis

C. coronata

C. hibiscifolia
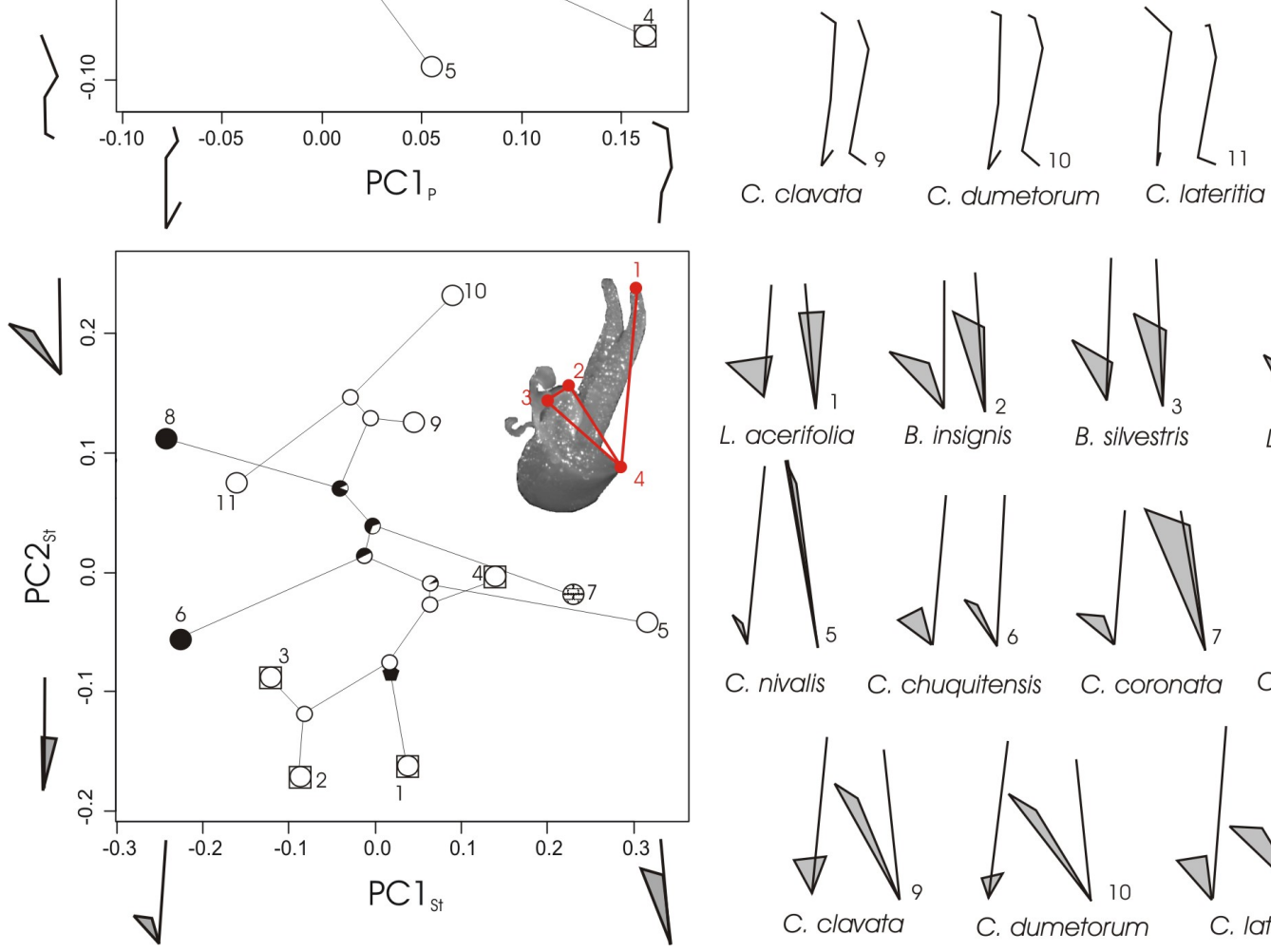

L. acerifolia
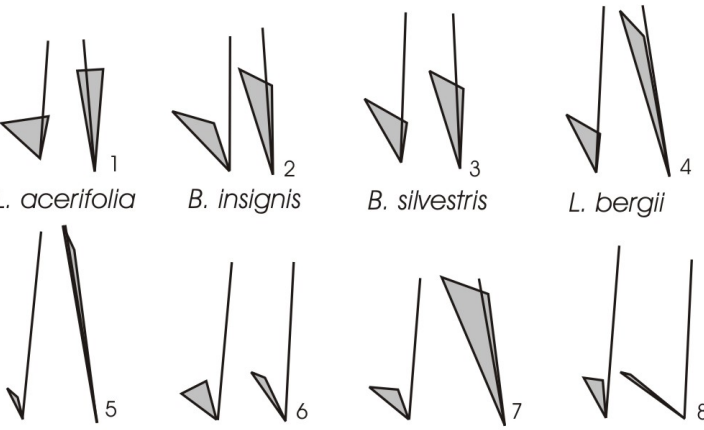

B. insignis

B. silvestris

L. bergii

C. nivalis C. chuquitensis
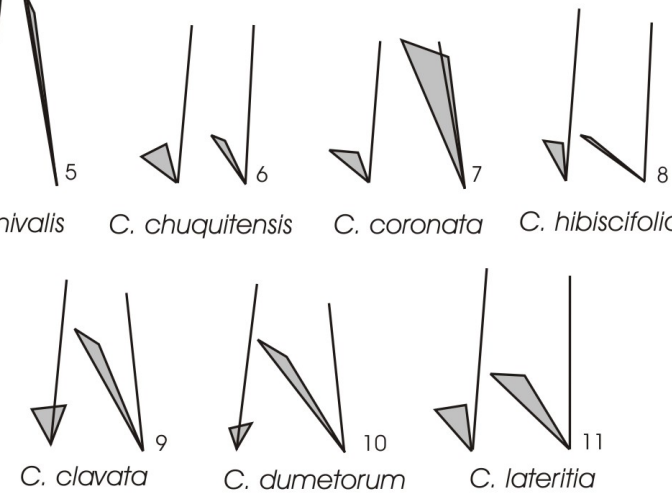

Figure 3. Ontogenetic allometries of the individual taxa and the allometric spaces of the petal (top) and of the staminode complex (bottom) in the 11 studied species. A photograph of the corresponding flower structure was added to each plot, showing the selected landmarks. The ontogenetic allometries of each species are represented next to 656 the corresponding allometric space. Development proceeds from left to right in each 657 representation. Species in Loasa and Blumenbachia are indicated with a square. 658 Pollination modes are represented: white $=$ bee pollination; black $=$ hummingbird 659 pollination; bricks $=$ small rodent pollination. The posterior probability of pollination 
660 modes is represented on each node. This information was obtained from Strelin et al.

661 (2017). The root of the phylogeny is indicated with a polygon.

662

663 